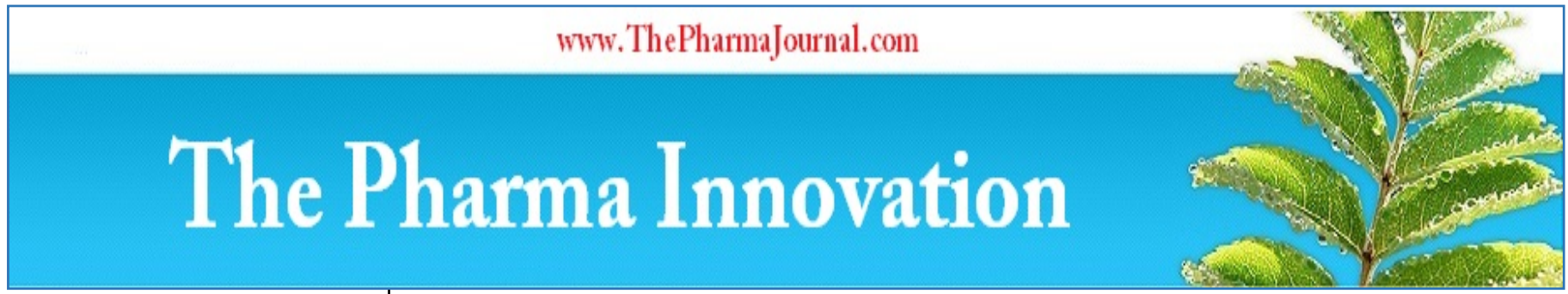

ISSN (E): 2277- 7695

ISSN (P): 2349-8242

NAAS Rating: 5.23

TPI 2021; SP-10(8): 721-725

(C) 2021 TPI

www.thepharmajournal.com

Received: 13-06-2021

Accepted: 15-07-2021

Tripti Ganjeer

Department of Veterinary Public

Health \& Epidemiology, College of

Veterinary Science and Animal

Husbandary, Dau Shri Vasudev

Chandrakar Kamdhenu University,

Anjora, Durg, Chhattisgarh, India

Anil Patyal

Department of Veterinary Public Health \& Epidemiology, College of Veterinary Science and Animal Husbandary, Dau Shri Vasudev Chandrakar Kamdhenu University, Anjora, Durg, Chhattisgarh, India

Sanjay Shakya

Department of Veterinary Public Health \& Epidemiology, College of Veterinary Science and Animal Husbandary, Dau Shri Vasudev Chandrakar Kamdhenu University, Anjora, Durg, Chhattisgarh, India

\section{Siddhant S Parka}

Department of Veterinary Public Health \& Epidemiology, College of Veterinary Science and Animal Husbandary, Dau Shri Vasudev Chandrakar Kamdhenu University, Anjora, Durg, Chhattisgarh, India

\section{Ankit Shukla}

Department of Veterinary Public Health \& Epidemiology, College of Veterinary Science and Anima Husbandary, Dau Shri Vasudev

Chandrakar Kamdhenu University, Anjora, Durg, Chhattisgarh, India

Choodamani Chandrakar Department of Veterinary Publi Health \& Epidemiology, College of Veterinary Science and Animal Husbandary, Dau Shri Vasudev Chandrakar Kamdhenu University, Anjora, Durg, Chhattisgarh, India

Vivek Naik

Department of Veterinary Public Health \& Epidemiology, College of Veterinary Science and Animal Husbandary, Dau Shri Vasudev Chandrakar Kamdhenu University Anjora, Durg, Chhattisgarh, India

\section{Corresponding Autho}

Tripti Ganjeer

Department of Veterinary Public

Health \& Epidemiology, College of

Veterinary Science and Animal

Husbandary, Dau Shri Vasudev

Chandrakar Kamdhenu University,

Anjora, Durg, Chhattisgarh, India

\section{Rodent borne zoonoses: A brief review}

\author{
Tripti Ganjeer, Anil Patyal, Sanjay Shakya, Siddhant S Parkar, Ankit \\ Shukla, Choodamani Chandrakar and Vivek Naik
}

DOI: https://doi.org/10.22271/tpi.2021.v10.i8Sk.7406

\begin{abstract}
Rodents are the most abundant and diversified order of living mammals in the world. Since the middle ages they are known to contribute to human diseases, eg. black rats associated with distribution of plague. In modern times also rodents form a threat for public health and a number of pathogens are directly or indirectly transmitted by rodents. Of 2277 extant rodent species, 217 species are reservoirs harboring 66 zoonoses caused by viruses, bacteria, fungi, helminths, and protozoa and play a major role in their transmission and spread in different ways. Among the most important diseases in terms of public health are salmonellosis, plague, leptospirosis, leishmaniasis, toxoplasmosis, rat-bit fever, taeniasis-like Capillaria hepatica, zoonotic babesiosis, Lassa fever, hemorrhagic fever with renal syndrome (HFRS), and the hantavirus cardiopulmonary syndrome (HCPS). In addition, Arenaviruses are responsible for South American Hemorrhagic Fevers (SAHF). Rodents may harbor different complex bacteria, such as Mycobacterium tuberculosis and Mycobacterium microti, Escherichia coli, agents of Tularemia, Tickborne relapsing fever, Bartonellosis, Listeriosis, Lyme disease, Q fever, Ehrlichiosis and others. Recent changes in the global climate and ecosystem composition led to the spread of rodents and rodent-borne pathogens globally. Rodent control in rural environments relies mainly on the use of rodenticides. Other management methods which can be applied are trapping, habitat management (e.g., proofing, sanitation), and biocontrol (e.g., wild or domestic predators, rodent pathogens).
\end{abstract}

Keywords: rodent, zoonoses, control methods

\section{Introduction}

Rodents animportant reservoir of human pathogens (Christova et al., 2014) ${ }^{[6]}$. Among 2277 rodent species, 217 species act as reservoirs for 66 zoonotic diseases caused by viruses, bacteria, fungi, helminths, and protozoa (Han et al., 2015) ${ }^{[13]}$ and play a major role in their transmission and spread. The different rodent borne zoonotic diseases are Salmonellosis, Plague, Leptospirosis, Leishmaniasis, Toxoplasmosis, Rat-bit fever, Taeniasis-like Capillaria hepatica, zoonotic babesiosis, Lassa fever, hemorrhagic fever with renal syndrome (HFRS) and the hantavirus cardiopulmonary syndrome (HCPS) (Table 1). In addition, Arenaviruses are responsible for South American Hemorrhagic Fevers (SAHF). Rodents may harbor different complex bacteria, such as Mycobacterium tuberculosis and Mycobacterium microti, Escherichia coli, agents of tularemia, tick-borne relapsing fever, bartonellosis, listeriosis, Lyme disease, Q fever, ehrlichiosis and others. Most of them are important diseases in terms of public health (Dahmana et al., 2020) ${ }^{[7]}$.

Rodentia are distributed on every continent except Antarctica and contribute about $43 \%$ of the total number of mammalian species. They live in close contact with human populations, farm animals or pets. In peri-urban areas rodents provide connection between wildlife communities and humans and exposing humans to some zoonoses circulating in these natural ecosystems (Meerburg et al., 2009) ${ }^{[18]}$.

Rodent-borne diseases transmitted directly or indirectly. In direct transmission, diseases are transmitted by biting or by inhaling the germ containing feces of rodents, whereas in indirect transmission, humans are infected by consuming food and water contaminated by rodent feces or urine. Likewise, in the case of diseases transmitted by arthropod vectors from rodents to humans rodents could act as amplifier host (Rabiee et al., 2018) ${ }^{[23]}$. 
Table 1: The important rodent borne diseases prevalent in India are as follows

\begin{tabular}{|c|c|c|}
\hline Disease & Agent & Rodents as Carrier/Reservoir \\
\hline Leptospirosis & L. icterohemorrhagiae & Carrier \\
\hline Salmonellosis & S. enteritidis & Carrier \\
\hline Tularemia & Francisella tularensis & Carrier \\
\hline Listeriosis & L. monocytogens & Carrier \\
\hline Plague & Yersina pestis & Reservoir \\
\hline Lyme disease & Borrelia burgodorferi & Reservoir \\
\hline Scrub typhus & Orientia tsutsugamushi & Reservoir \\
\hline Murine typhus & Rickettsia typhi & Reservoir \\
\hline Rickettsialpox & Rickettsia akari & Reservoir \\
\hline Q fever & Coxiella burnetii & Reservoir \\
\hline Rat bite fever & Streptobacillus moniliformis & Reservoir \\
\hline Hantavirus & Hantavirus, Bunyaviridae family & Carrier \\
\hline Crimean-Congo hemorrhagic fever & CCHF, Bunyaviridae family & Reservoir \\
\hline Kyasanur Foest Disease & KFDV, Flaviviridae & Reservoir \\
\hline Tick borne encephalitis & TBEV, Flaviviridae & Reservoir \\
\hline Lassa Fever & LASV, Arenaviridae & Carrier \\
\hline Lymphocytic Choriomeningitis (LCMV) & LCMV, Arenaviridae & Reservoir \\
\hline Venezuelan hemorrhagic fever & Guanarito virus, Arenaviridae & Carrier \\
\hline Hepatitis E & HEV, Calciviridae & Rservoir \\
\hline Toxoplasmosis & Toxoplasma gondii & Reservoir \\
\hline Babesiosis & B. microti & Reservoir \\
\hline Cryptosporidiosis & Cryptosporidium & Reservoir \\
\hline Chagas disease & Trypanosome cruzi & Reservoir \\
\hline Leishmaniasis & Leishmenia donovani & Reservoir \\
\hline Giardiasis & Giardia lamblia & Reservoir \\
\hline Human fascilosis & Fasciola hepatica, F. gigantic & Reservoir \\
\hline Taeniasis & Taenia solium in pork Taenia saginata in beef & Reservoir \\
\hline
\end{tabular}

\subsection{Plague}

Plague is a rodent-borne bacterial zoonotic disease caused by Yersinia pestis, a member of the Enterobacteriaceae family. It is gram-negative bacillus. In human it may occasionally transmitted and has complex zoonotic/epizootic cycles, it can cause sporadic cases, outbreaks, or even large epidemics. Among humans, bubonic plague is the most common clinical presentation. Bubonic forms may develop to septicemic disease, and 1 to $3 \%$ develops to secondary pneumonic plague and it may be transmitted from person to person through respiratory droplets. Following the onset of symptoms between 1 to 4 days, the mortality may be up to $100 \%$ in untreated cases (Vallès et al., 2020) ${ }^{[29]}$. In rodents the bacterium is enzootic. The most common hosts are Rattus rattus (the domestic black rat) and Rattus norvegicus (the brown sewer rat) and Xenopsylla cheopis (the oriental rat flea) is the most common and efficient vector. (Dillard and Juergens, 2020) ${ }^{[9]}$.

Currently, $>95 \%$ of human plague cases reported in subSaharan Africa, mainly in Madagascar and the Ituri region of the Democratic Republic of Congo (DRC). During 20082016, in the plague-endemic West Nile region of Uganda, 255 suspected human plague cases were recorded during active surveillance followed by laboratory testing (Forrester et al., 2017) ${ }^{[10]}$.

WHO notified 2,886 cases and 504 deaths between 2013 and 2018, (with a reported case fatality of $17.5 \%$ ) Scattered cases of human plague are regularly reported from China, Mongolia, the Russian Federation, Kyrgyzstan, Peru, Bolivia, Uganda, Tanzania, and the US. Nowadays, $Y$. pestis is present in at least 33 countries in the last 30 years. More than 200 mammals (mainly rodents and lagomorphs) have been reported to be infected and about 30 different flea vectors have been suspected to play a role in transmission, including potential reservoir hosts, in different parts of the world
(Vallès et al., 2020) ${ }^{[29] . ~}$

\subsection{Leptospirosis}

The rodents role in Leptospira epidemiology and transmission is well known worldwide. Wild rats (Rattus spp.), especially the Norway/brown rat (Rattus norvegicus) and the black rat ( $R$. rattus), are the most important carriers of different pathogenic serovars of Leptospira spp, capable of causing disease in humans and animals. Rats are maintaining the spirochetes in their proximal renal tubules (Boey et al., 2019) [4].

World Health Organization (WHO) reported Leptospirosis as a major emerging and re-emerging disease widely spread among humans and animals, globally it is estimated that more than 1 million people has been infected with 60,000 deaths per year worldwide (Karpagam et al., 2020) ${ }^{[16]}$. In tropical regions, including the Asia-Pacific, Latin America, and the Caribbean has found highest incidence of Leptospirosis with an estimation of $>10$ cases per 100,000 population per year. Frequent outbreaks occur in urban slum areas following heavy seasonal rains, most notably during 2007 and 2009 in Nicaragua and the Philippines (Taylor et al., 2015) ${ }^{[28]}$. In Malaysia Leptospirosis is a notifiable disease and number of cases has gradually increased from 1976 to 4557 during the year 2010 to 2013.In these two years up to $72.3 \%$ of cases were diagnosed in males while $51.6 \%$ in older than 30 years. The number of fatal cases increases to 71 cases in 2013 and 92 cases in 2014. In India, Leptospirosis has numerous outbreaks in the last decade. In Sri Lanka it is endemic with 7000 reported cases during 2008. In South America Leptospirosis is a prominent cause of febrile illnesses. In Brazil Every year, outbreaks occur in the urban slum areas, primarily due to heavy rainfall, flooding, and poor sanitation. Higher incidence of cases shows the threat of Leptospirosis to public health and also places the burden of disease on other 
developing countries in Asia and beyond (Soo et al., 2019) [27].

\subsection{Scrub typhus}

Scrub typhus is an emerging rodent-borne zoonotic disease. It is caused by Orientia spp. and transmitted by larvae of trombiculid mites, called chiggers. Disease is found in AsiaPacific region called as tsutsugamushi triangle (Acosta-Jamett et al., 2020) ${ }^{[1]}$. This pathogen is transmitted by bites of infected trombiculid mites ('chiggers') which are hosted by various rodent species, such as the Norway rat $(R$. norvegicus), the lesser bandicoot (Bandicoota bengalensis), the bandicoot rat (Bandicoota indica), house mouse (Mus musculus), the striped-field mouse (Apodemus agrarius), and the Japanese grass vole Microtus montebelli(Kumar et al., 2004) ${ }^{[17]}$.

Geographic distribution of the disease occurs within an area of about 13 million $\mathrm{km}^{2}$ including Afghanistan and Pakistan to the west; Russia to the north; Korea and Japan to the northeast; Indonesia, Papua New Guinea, and northern Australia to the south; and some smaller islands in the western Pacific. It was first observed in Japan where it was found to be transmitted by mites (NCDC, 2009) ${ }^{[20]}$.

Incidence of Scrub typhus was reported from Gorakhpur district, Uttar Pradesh, India, during cooler season of the year (October to December) where, 63\% of patients reported with AES and 54\% of patients with acute febrile illness. It is also reported from Asam with 20\% of AES. in the year 2010 human scrub typhus cases were reported from Pondicherry. Pondicherry, and the adjoining regions of Tamil Nadu recorded the abundance of vector mite, Leptotrombidium deliense, and the pathogen, O. tsutsugamushi in rodents but no reports of human scrub typhus cases (Devaraju et al., 2020) ${ }^{[8]}$.

\subsection{Kyasanur forest disease}

Kyasanur Forest Disease (KFD) is a re-emerging zoonotic disease caused flavivirus which is found in forest rodents in south western India (Meerburg et al., 2009) ${ }^{[18]}$. Disease is associated with sudden onset of high-grade fever, prostration, nausea, vomiting, diarrhea and occasionally neurological \& haemorrhagic manifestations. Infected ticks are the source of infection to human.

KFD was initially reported in black-faced langur (Semnopithecus entellus) and red-faced bonnet monkeys (Macaca radiata) in Kyasanaur forest of Shimoga district in India. About 400-500 humans were also affected with the disease who had visited the affected forest at that time. The tick species Haemaphysalis spinginera is widely distributed in the deciduous and evergreen forests of India and Sri Lanka. KFD was reported to be endemic in Sagar, Sorab, and Shikarpur taluks of district Shimoga. Many sporadic cases of KFDV have been also observed every year in the endemic state of Karnataka mostly in Shimoga, Chikmagalur, Udupi, Uttar Kannada, and Dakshina Kannada district since 1957, after the discovery. During the year 2004-2012, many outbreaks occur in four districts of Karnataka state with 556 reported human cases. KFD outbreak was also reported in the Bandipur Tiger Reserve in Chamarajanagar among the forest workers during 2012 to 2013. During the same period, in Nilgiri and Wayanad the virus was detected in ticks and/or monkeys. During 2014-2015, in new regions of Wayanad and Malappuram districts of Kerala, KFD outbreaks were explicitly observed and more recently, it has been reported in
Goa, India ( Shah et al., 2018) ${ }^{[25] .}$

\subsection{Hantavirus}

Hantavirus is a negative-sense, single-stranded, tripartite RNA genome and hosted by rodents. (Kang et al., 2011) ${ }^{[15]}$. "New World" hantaviruses found in America cause hantavirus pulmonary syndrome (HPS) and in Europe and Asia found "Old World" hantaviruses, it may cause hemorrhagic fever with renal syndrome (HFRS) (CDC, 2020) ${ }^{[20]}$.

Rodents that carry hantavirus are Murinae and Arvicolinae subfamilies cause hemorrhagic fever with renal syndrome, while subfamilies Neotominae and Sigmodontinae cause hantavirus cardiopulmonary syndrome. Puumala virus, an arvicoline-borne virus, are also associated with HFRS. Hantaan virus and Seoul virushas a worldwide distribution hosted by Apodemus agrarius and Rattus norvegicus. Bandicota indicaare host for Thailand virus and present in Thailand. In Indonesia Serang virus has been recently identified and hosted by $R$. tanezumi and Thottapalayam virus, found in India (Blasdell et al., 2011) ${ }^{[3]}$.

HPS cases have been reported in South American and other North American countries, as in Balkans, Northern Sweden, Argentina, Poland, Chile, Bolivia, Brazil, Serbia, United Kingdom, Panama, Germany, and Russia. In the year 2014, Europe reported the incidence of HV infections with 3754 confirmed cases. From 1997 to 2011 gradual increase in the HPS cases were reported anuaaly in Argentina. Southern Argentina reported death of 11 individuals between 2018 and 2019. Canada reported, a total of 109 confirmed cases and 27 deaths because of HPS in January 2015. In Chile 93 number of cases reported during 2011, and during the year 2018, eight confirmed cases were reported that include two deaths. Most recently in 2019, first confirmed case found in the Los Lagos Region of Chile (Hangaragi et al., 2020) ${ }^{[14]}$.

First indigenous Indian HV species, Thottapalayam virus (TPMV), was isolated in 1964 in South India from the spleen of a non-rodent house shrew, during studies of Japanese encephalitis in the population. It was reported that $14.7 \%$ of 152 individuals with febrile illness and $5.7 \%$ of 87 voluntary healthy donors were anti-HV IgM positive. This study suggested the possibility of asymptomatic and symptomatic HV infections in the South Indian population. HV-specific IgM has been detected as early as 3 days after onset of illness. Another seroprevalence study revealed higher $\mathrm{HV}$ specific IgG in the risk group (11\%) as compared to a healthy blood donor group (4\%) gave the first evidence of fatal $\mathrm{HV}$ nephropathy in India (Hangaragi et al., 2020) ${ }^{[14]}$.

\subsection{Crimean Congo Haemorrhagic Fever (CCHF)}

Crimean-Congo haemorrhagic fever (CCHF) is a tick-borne viral disease caused by the CCHF virus (CCHFV), an RNA negative single-stranded virus of the genus Nairovirus in the Nairoviridae family. The virus has been identified in Africa, Asia and Europe in territories located south of the 50th North parallel, the area inhabited by the main vector, ticks of the genus Hyalomma spp. CCHFV is implicated in outbreaks with a very high mortality rate (10-40\%) (Artega et al., 2020) ${ }^{[2]}$. CCHF has been isolated from rodents thus, play a important role in the tick cycle (Nalca and Whitehouse, 2007) ${ }^{[19]}$.

CCHF is endemic in Africa, Balkans, Middle East and Asia with estimated cases of 10,000 to 15,000 each year (WHO, 2018) ${ }^{[30]}$. CCHF is considered an emerging disease in 
southern Europe. Moreover, imported cases have been detected in France and the United Kingdom (UK) in 2004 and 2013, respectively (Artega et al., 2020) ${ }^{[2]}$. CCHF infection is also detected from Pakistan during 2015 to 2017 where prevalence higher in rural areas. (Zohaib et al., 2020) ${ }^{[31]}$. In India CCHF has been reported from Gujarat since 2011 to 2019. CCHF outbreak was also recorded from three districts Jodhpur, Jaisalmer, and Sirohi of Rajasthan state since August 2019 till November 2019 (Sahay et al., 2020) ${ }^{\text {[24] }}$.

\subsection{Toxoplasmosis}

Toxoplasmosis is caused by the intracellular protozoan parasite Toxoplasma gondii (T. gondii) it is one of the most prevalent infections in humans and animals. Rodents act as intermediate and reservoir hosts and play a key role in the maintenance and transmission of $T$. gondii. They can maintain the parasite in the form of cysts in their bodies, act as an infection source for their offsprings, predators (particularly felids), and other animals. Direct transmission of toxoplasmosis from rodents to humans may occur when they are consumed as food by humans, as it is done by many human populations (Galeh et al., 2020) ${ }^{[11]}$.

Parasite has a two-stage asexual cycle in warm-blooded animals and a sexual cycle in felidae. In the asexual cycle, the two developmental stages are the rapidly multiplying tachyzoite and the slowly multiplying bradyzoite. In acute infection, tachyzoites actively penetrate host cells where they multiply causing the cell to rupture and release organisms locally and into the bloodstream. The sexual cycle occurs in enteroepithelial cells of the feline definitive host and results in the production of Toxoplasma oocysts. Following a primary infection of a cat, oocysts may be shed in the faeces for several days. The oocysts sporulate in the environment over the next 1-5 days (depending on aeration, humidity and temperature), at which time they become infective (OIE, 2017) ${ }^{[21]}$.

In humans, toxoplasmosis has been found globally and it is estimated about one-third of the world's population is infected with latent toxoplasmosis. Latin America, parts of Eastern/Central Europe, the Middle East, and parts of southeast Asia and Africa are high prevalence areas. In US seroprevalence for $T$. gondii in cats is 30 to $40 \%$ with regional prevalence varying with climate; prevalence being lowest in the drier southwestern regions (16.1 \% in New Mexico, Utah and Arizona) and highest in humid areas (59.2\% for Hawaii) (Halonen and Weiss, 2013) ${ }^{[12]}$.

\section{Rodent control strategies and methods}

The rodent population can be controlled by regulating the births, deaths, immigration or and emigration the population size may be regulated which occur at rates that depend on population density. The immigration can be prevented and reduced by using barrier methods, rodent proofing premises, electric fences, diversion feeding, ultrasound and electromagnetic devices and chemical repellents. Pest birth rate can be reduced effectively by implemented by removal of nesting opportunities- Clean farming practices and sanitation measures, the odours and ultrasonic devices has a potential of disruption of reproductive behavior in house mice. The alphachlorohydrin (Epibloc $\left.{ }^{\circledR}\right)$, a male antifertility compound also has good result. The pest death rate can be enhanced by trapping and hunting and using the predators viz feral cat, barn owls, Indian mongoose (Smith and Meyer, 2015) ${ }^{[26]}$.

The acute rodenticides zinc phosphide, aluminium phosphide, barium carbonate, arsenic trioxide, strychnine alkaloid, thallium sulphate, alphanapthyl thiourea (ANTU), norbormide, scillirocide (red squill); sodium fluroacetate, vacor (RH-787) and a gophacide have very good results. Similarly rodenticides with subacute action, are bromethalin, flupropadine, calciferol (ergocalciferol, vitamin D2) and cholecalciferol (vitamin D3). The first-generation anticoagulantsIt includes warfarin, fumarin,coumatetralyl, diphacinone and chlorophacinone. And second-generation anticoagulantssecond generation anticoagulant rodenticides are difenacoum, brodifacoum, bromadiolone, flocoumafen and difethiolone (Smith and Meyer, 2015; Parshad, 1998) [26, 22].

\section{Conclusion}

Besides economic losses through spoilage of feed or structural damage, rodent presence on livestock farms can have serious consequences for public and animal health. Rodents play a significant role in transmission of a large number of diseases to humans. The risk levels vary between the different pathogens, a better surveillance of rodent populations is important in order to predict future disease prevalence.

\section{References}

1. Acosta-Jamett G, Martínez-Valdebenito C, Beltrami E, Silva-de La Fuente MC, Jiang J, Richards AL et al. Identification of trombiculid mites (Acari: Trombiculidae) on rodents from Chiloé Island and molecular evidence of infection with Orientia species. PLoS Negl Trop Dis 2020;14(1):e0007619.

2. Arteaga LM, Bellido JLM, Lista MCV, Santiago MBV, Soto PF, Bas I et al. Crimean-Congo haemorrhagic fever (CCHF) virus-specific antibody detection in blood donors, Castile-León, Spain, summer 2017 and 2018. Eurosurveillance 2020;25(10):1900507.

3. Blasdell K, Cosson JF, Chaval Y, Herbreteau V, Douangboupha B, Jittapalapong S et al. Rodent-Borne Hantaviruses in Cambodia, Lao PDR, and Thailand. EcoHealth 2011;8(4):432-443.

4. Boey K, Shiokawa K, Rajeev S. Leptospira infection in rats: A literature review of global prevalence and distribution. PLoS Negl Trop Dis 2019;13(8):e0007499.

5. Centers for disease control and prevention, 2020, Hantavirus [Weblink:

https://www.cdc.gov/hantavirus/index.html] [Visited on 31 January 2021]

6. Christova I, Trifonova I, Kalvatchev N, Dimitrov H, Mitkovska V, Gladnishka T et al. Rodents as reservoirs of human pathogens in Bulgaria. Parasites \& Vectors, 2014;7(1):12.

7. Dahmana H, Granjon L, Diagne C, Davoust B, Fenollar F, Mediannikov O. Rodents as hosts of pathogens and related zoonotic disease risk. Pathogens 2020;9(3):202.

8. Devaraju P, Arumugam B, Mohan I, Paraman M, Kashinathan G, Purushothaman J. Evidence of natural infection of Orientia tsutsugamushi in vectors and animal hosts- Risk of scrub typhus transmission to humans in Puducherry, South India. Indian journal of public health, 2020;64(1):27-31.

9. Dillard RL, Juergens AL. Plague. Stat Pearls [Internet]. 2020.

10. Forrester JD, Apangu T, Griffith K, Acayo S, Yockey B, Kaggwa $\mathrm{J}$ et al. Patterns of Human Plague in Uganda, 2008-2016. Emerging Infectious Diseases 
2017;23(9):1517-1521.

11. Galeh TM, Sarvi S, Montazeri M, Moosazadeh M, Nakhaei M, Shariatzadeh SA et al. Global Status of Toxoplasma gondii Seroprevalence in Rodents: A Systematic Review and Meta-Analysis. Frontiers in Veterinary Science 2020, 7.

12. Halonen SK, Weiss LM. Toxoplasmosis. Handbook of clinical neurology 2013;114:125-145.

13. Han BA, Schmidt JP, Bowden SE, Drake JM. Rodent reservoirs of future zoonotic diseases. Proceedings of the National Academy of Sciences 2015;112(22):7039-7044.

14. Hangaragi PS. Hantavirus: An emerging global threat. Asian J Oral Health Allied Sci 2020;10:4

15. Kang HJ, Bennett SN, Hope AG, Cook JA, Yanagihara R. Shared Ancestry between a Newfound Mole-Borne Hantavirus and Hantaviruses Harbored by Cricetid Rodents. Journal of Virology 2011;85(15):7496-7503.

16. Karpagam KB, Ganesh B. Leptospirosis: a neglected tropical zoonotic infection of public health importance-an updated review. Eur J Clin Microbiol Infect Dis 2020;39:835-846

17. Kumar K, Saxena VK, Thomas TG, Lal S. Outbreak investigation of scrub Typhus in Himachal Pradesh (India). J Commun Dis 2004;36(4):277-83.

18. Meerburg BG, Singleton GR, Kijlstra A. Rodent-borne diseases and their risks for public health. Critical reviews in microbiology 2009;35(3):221-270.

19. Nalca A, Whitehouse CA. Crimean-Congo Hemorrhagic Fever Virus Infection among Animals. Crimean-Congo Hemorrhagic Fever, 2007, 155-165.

20. NCDC, Scrub 2009, typhus [Weblink: https://ncdc.gov.in/WriteReadData/linkimages/May\%20J une-20098604739980.pdf] [Visited on 4 January 2021]

21. OIE 2017 Toxoplasmosis [Weblink: https://www.oie.int/fileadmin/Home/eng/Health_standard s/tahm/2.09.09_TOXO.pdf] [Visited on 28 January 2021]

22. Parshad VR. Rodent control in India. Integrated Pest Management Reviews 1999;4(2):97-126.

23. Rabiee MH, Mahmoudi A, Siahsarvie R, Kryštufek B, Mostafavi E. Rodent-borne diseases and their public health importance in Iran. PLoS neglected tropical diseases 2018;12(4):e0006256.

24. Sahay RR, Dhandore S, Yadav PD, Chauhan A, Bhatt L, Garg $\mathrm{V}$ et al. Detection of African genotype in Hyalomma tick pools during Crimean Congo hemorrhagic fever outbreak, Rajasthan, India, 2019. Virus Research, 2020;286:198046.

25. Shah SZ, Jabbar B, Ahmed N, Rehman A, Nasir H, Nadeem $\mathrm{S}$ et al. Epidemiology, Pathogenesis, and Control of a Tick-Borne Disease- Kyasanur Forest Disease: Current Status and Future Directions. Frontiers in Cellular and Infection Microbiology 2018, 8

26. Smith RH, Meyer AN. Rodent control methods: nonchemical and non-lethal chemical, with special reference to food stores. Rodent pests and their control, 2nd Edn. CAB International, Boston 2015, 101-122.

27. Soo ZMP, Khan NA, Siddiqui R. Leptospirosis: Increasing importance in developing countries. Acta Tropica, 105183. 2019.

28. Taylor AJ, Paris DH, Newton PN. A Systematic Review of the Mortality from Untreated Leptospirosis. PLoS Negl Trop Dis 2015;9(6):e0003866.

29. Vallès X, Stenseth NC, Demeure C, Horby P, Mead PS, Cabanillas $\mathrm{O}$ et al. Human plague: An old scourge that needs new answers. PLoS Negl Trop Dis 2020;14(8):e0008251.

30. WHO Introduction to Crimean-Congo Haemorrhagic Fever 2018 [Weblink: file://C:/Users/k/Downloads/introduction-to-crimeancongo-haemorrhagic-fever\%20(1).pdf] [Visited on 9 February 2021]

31. Zohaib A, Saqib M, Athar MA, Hussain MH, Sial AUR, Tayyab $\mathrm{MH}$ et al. Crimean-Congo hemorrhagic fever virus in humans and livestock, Pakistan, 20152017. Emerging infectious diseases 2020;26(4):773. 